\title{
Correlation between Epicardial Fat Thickness and Clinical and Anthropometric Variables in an Elderly Population
}

\author{
Joaquim Castanheira ${ }^{\circledR}$, Cristiana Nunes $^{\circledR}$, Telmo Pereira ${ }^{\circledR}$ \\ Instituto Politécnico de Coimbra - Escola Superior de Tecnologia da Saúde de Coimbra, Coimbra - Portugal
}

\section{Abstract}

Background: Epicardial fat (EF) thickness is a marker of visceral adiposity and consequently considered an important predictive marker of cardiovascular and metabolic risk.

Objective: To describe echocardiographic features of the heart in an elderly population and to study the correlation between EF thickness and clinical and anthropometric variables.

Methods: A sample of 34 individuals ( 25 women) aged between 65 and 92 years, who attended a private institution in the central region of Continental Portugal, was analyzed. A standardized sociodemographic questionnaire was applied, and anthropometric assessment, echocardiography and blood pressure measurement were performed in all subjects. A correlational analysis of EF thickness with anthropometric and clinical parameters was performed. The association between variables was tested by Pearson's correlation and point-biserial correlation. A value of $\mathrm{p}<$ 0.05 was defined as statistically significant.

Results: EF thickness was higher in males $(6.0 \pm 1.4 \mathrm{~mm}$ vs $5.2 \pm 0.9 \mathrm{~mm}$ in females), and ranged from 4 to $9 \mathrm{~mm}$. There were statistically significant correlations between $\mathrm{EF}$ thickness and weight $(\mathrm{r}=0.4 ; p=0.02)$, body surface area $(\mathrm{r}=0.4 ; p=0.02)$, lean mass $(\mathrm{r}=0.4 ; p=0.03)$, calf circumference $(\mathrm{r}=0.5 ; p=0.01)$ and left ventricular end-diastolic diameter $(\mathrm{r}=0.3 ; p=0.04)$.

Conclusion: EF thickness was higher in males and was significantly correlated with anthropometric parameters of adiposity and left ventricular end-diastolic diameter. (Int J Cardiovasc Sci. 2021; 34(2):136-146)

Keywords: Epicardial Fat; Echocardiography/methods; Anthropometry; Aging; Blood Pressure; Diabetes Mellitus; Hypertension; Risk Factors; Adiposity.

\section{Introduction}

Cardiac aging is characterized by slow and progressive changes in cardiac structure and function. With advancing age, although systolic ventricular function is relatively preserved, the same is not true for diastolic function. ${ }^{1}$ With aging, there are also changes in cardiac valves, mainly in the left valves, ${ }^{1}$ mainly calcification of the leaflets of the aortic and mitral valves. ${ }^{2}$ Although agerelated changes of the right valves are less frequent and milder, there is evidence of small fibroelastic nodules in the tricuspid valve, while the pulmonary valve remains almost unchanged. ${ }^{3,4}$
Epicardial fat (EF) is a component of the visceral fat located between the surface of the myocardium and the visceral layer of the pericardium..$^{5-13}$ It can be deposited throughout the entire myocardium, but it is predominant in the atrioventricular and interventricular sulci, extending to the apex and around the coronary arteries. ${ }^{6,8-9,14-16}$ The EF shares its embryological origin with the intra-abdominal visceral fat, ${ }^{10,14}$ and the microcirculation with the myocardium and coronary arteries. It can be a potential cause of local inflammation and has direct effects on coronary atherosclerosis through the release of anti- and pro-inflammatory substances, with correlations with the severity of metabolic syndrome and

Mailing Address: Telmo Pereira

São Martinho do Bispo. Postal Code: 3046-854, Coimbra - Portugal

E-mail: telmo@estescoimbra.pt 
heart diseases, especially coronary artery disease..$^{5-10,15-23}$ Although EF has been considered by some authors as an important predictive marker of cardiovascular and metabolic risk, ${ }^{8,16}$ its association with other risk factors in elderly populations, makes its interpretation as an independent risk marker difficult. ${ }^{8}$

The association of EF thickness with age and gender has been controversial in the published studies. While some authors have reported that EF thickness tends to increase with age, $, 19,22,24-28$ others have not found statistically significant correlations between these two variables.7,11-12, 29,30 Regarding gender, some authors 11,12,19,31 have reported higher EF thickness in males, while others ${ }^{7,25-32}$ found it to be higher in females. Regarding anthropometric parameters, EF thickness seems to correlate with weight, ${ }^{25-31,33}$ height, ${ }^{31}$ abdominal circumference, ${ }^{10-13,19,22,25,28,29,33-34}$ and fat mass, ${ }^{11,12}$ and and regarding the correlation correlation between EF thickness and body mass index (BMI) the results have been contradictory. ${ }^{2,9-12,22,25-26,28,29,31,33-34}$ The association of EF thickness with obesity has been widely described, ${ }^{11,16-}$ 17,31,35-37 and significant changes in EF thickness in severely obese individuals undergoing weight loss programs or interventions have been reported. ${ }^{30,37,38}$ Although the relationship between EF thickness and some clinical conditions such as diabetes and dyslipidemia is not in the literature, its correlation with hypertension seems to be more evident. ${ }^{11,24,30,33-34}$

In addition, several studies have found correlations between EF thickness and some echocardiographic parameters, such as left ventricular mass index (LVMI), ${ }^{24,29}$ left ventricular hypertrophy (LVH), ${ }^{14,18,26}$ and left ventricular diastolic dysfunction.,26,36

Thus, the interest in the study of the EF thickness through echocardiography has been growing, since it reflects the intra-abdominal visceral fat regardless of obesity degree and age (differently from anthropometry), and has been proposed as a marker of visceral adiposity. ${ }^{10,11,13-15,39}$ Apparently, some clinical and demographic characteristics of the populations ${ }^{8}$ have an influence on determining the EF thickness limits; even so, while Natale et al., ${ }^{24}$ have suggested an upper limit of $7 \mathrm{~mm}$ in a healthy population, Bertaso et al., ${ }^{8}$ have suggested that a thicknesses greater than $5 \mathrm{~mm}$ may already be considered abnormal in a low-risk population.

The aim of this study was to present echocardiographic features of the heart, with emphasis on EF characterization, and its correlations with clinical, anthropometric and other echocardiographic variables in an old adult population.

\section{Methods}

\section{Study Design, Sample and Ethical aspects}

An observational cross-sectional study was carried out with participants of the AGA@4life. The aim of the AGA@4life project is to evaluate the effect of a multidisciplinary and personalized intervention on promoting an active and healthy aging. This preliminary analysis, focused on the data obtained in the initial characterization of the studied population, aimed to identify characteristics of the heart, particularly the EF profile and its correlation with other clinical, anthropometric, and functional variables in adults. The sample was recruited by convenience at a private institution of social solidarity in the central region of Continental Portugal (ADIC, Vilarinho, Portugal). We included participants over the age of 65 , of both genders, physically independent and without previous history of cerebrovascular or cardiac disease. Thus, the sample was composed of 34 volunteer participants (9 men and 25 women), aged between 65 and 92 years.

The study complied with the recommendations of the Declaration of Helsinki and was approved by the Ethics Committee of the Polytechnic Institute of Coimbra. Anonymity and confidentiality of the data were guaranteed. The study was conducted for strictly scientific purposes, and there are no conflicts of interest to declare. All participants gave their informed consent to participate in the study.

\section{General Procedure}

Eligible elderly adults were invited to participate in the study in January 2018. During the months of February and March 2018, a diagnostic evaluation of each participant was carried out using a structured questionnaire designed for the study. Data on comorbidities, current medication use, nutritional profile, daily activity profile, cardiovascular risk profile and history of falls were collected. Blood and urine samples were collected for laboratory analysis and several diagnostic methods for the detection of multisystemic diseases were applied, whose results will not be discussed in the present study. An echocardiography, and anthropometric and brachial blood pressure (BP) measurements were performed. 


\section{Echocardiographic evaluation}

Analysis of echocardiographic variables was made by a single and experienced operator, using a Vivid 7 echocardiography device with an echocardiography device (GE Medical, Milwaukee, WI, USA) with a 1.7-3.2 MHz multi-frequency linear probe. All echocardiographic studies were performed according to the recommendations of the American Society of Echocardiography and the European Association of Cardiovascular Imaging. ${ }^{40,41}$ An M-mode and two-dimensional echocardiography was performed, with measurement of heart chamber dimensions, left ventricular (LV) wall thickness, and aortic root diameter. The EF thickness was measured at endsystole perpendicularly to the right ventricular free wall in parasternal view (long- and short-axis), in three consecutive cardiac cycles, and defined as the echo-free space between the myocardial surface and the visceral layer of the pericardium, ${ }^{5-7,11-15,32}$ as previously described by Iacobellis et al., ${ }^{11-15}$ (Figure 1).

\section{Anthropometry}

Height was measured in centimeters, with the participant standing barefoot, with the back straight, against the stadiometer, feet together and head in the
Frankfurt position (lower orbital arch aligned horizontally with the ear). Weight was determined in kilograms, and lean and fat masses, expressed as percent, were calculated by bioelectrical impedance analysis using the InBody 230 equipment. Body surface area (BSA, $\mathrm{m}^{2}$ ) was calculated using the Dubois \& Dubois formula, and the BMI using the Quetelet index. Abdominal circumference was measured with the individual without clothes, abdomen relaxed, arms hanging freely, palms facing inwards, head upright and feet together. For practical purposes and to reduce the margin of error, the measurement was taken at the end of the respiratory cycle, with the tape snug to the skin but not compressing it. Two measurements were taken, and the mean of these two measurements was used for analysis. Waist circumference measured during expiration, at the midway between the last costal arch and the iliac crest. Hip circumference was measured at the level of the maximum prominence of the buttocks in a horizontal plane. Calf circumference was measured in duplicate, at the point of maximal circumference of the lower right leg, and the mean of these two measurements was used in the analysis.

\section{Blood Pressure measurement}

Blood pressure measurements were automatically obtained using the Mobil-o-Graph equipment (IEM,

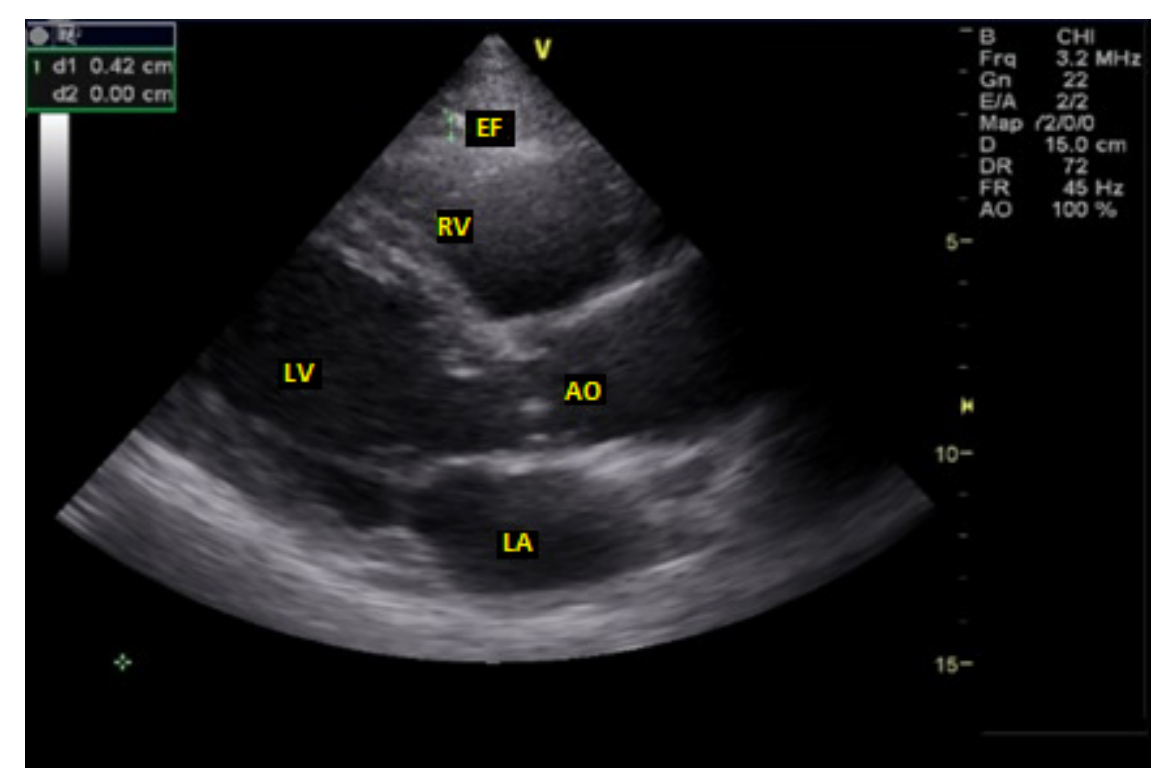

Figure 1 - Measurement of epicardial fat by transthoracic echocardiography in the long-axis parasternal view. EF: epicardial fat; $R V$ : right ventricle; $L V$ : left ventricle; $A O$ : aorta; $L A$ : left atrium 
Stolberg, Germany). Subjects were instructed to refrain from tobacco and caffeine for at least 2 hours prior to the study. Blood pressure was measured at the brachial artery, in sitting position, after a resting period of 5 minutes, with the arm supported at heart level and without constrictive clothing. Three measurements were taken, and the mean was considered for analysis.

\section{Statistical Analysis}

The statistical analysis was performed using the Statistical Program for Social Sciences - SPSS, version 24 (IBM, Armonk, NY).

The categorical variables were reported as frequency and percentages, and the $\chi 2$ test or the Fisher Exact test were used when appropriate. The Shapiro-Wilk test was used to confirm the normal distribution of all continuous variables, which were presented as mean and standard deviation.

To determine the degree of association between the variables, Pearson's correlation coefficient and pointbiserial correlation coefficient (when one of the variables was categorical) were used. The correlation coefficients were interpreted according to the literature, that is, as trivial $(\mathrm{r}<0.1)$, small $(0.1<\mathrm{r}<0.3)$, moderate $(0.3$ $<\mathrm{r}<0.5)$, large $(0.5<\mathrm{r}<0.7)$, very large $(0.7<\mathrm{r}<0.9)$ and almost perfect $(\mathrm{r}>0.9) .{ }^{42}$ A value of $p<0.05$ was defined as a criterion of statistical significance for a 95 $\%$ confidence interval.

\section{Results}

Mean age of the sample was $81.9 \pm 7.8$ years, mean weight $65.8 \pm 11.6 \mathrm{~kg}$, and mean BMI was $28.2 \pm 4.1 \mathrm{~kg} / \mathrm{m}^{2}$. The results obtained from the questionnaire showed that $17.6 \%$ of the individuals had a family history of cardiovascular disease, $23.5 \%$ were diabetic and $55.9 \%$ had dyslipidemia. Echocardiography revealed both structural and functional cardiac changes, which is in accordance with the fact that the sample was composed of a very elderly population $-88 \%$ of individuals had aortic fibrosis (...), 73\% had mitral fibrosis, and $29 \%$ had tricuspid valve regurgitation (four with pulmonary artery systolic pressure greater than $35 \mathrm{mmHg}$ ). No significant changes were detected in the pulmonary valve. Other less frequent changes were changes in the left ventricular (LV) segmental contractility, basal septal hypertrophy (BSH), calcification of the mitral valve annulus and ascending aorta dilatation. General characteristics of the study sample are presented in Table 1.
Mean heart rate was $68.7 \pm 11.6 \mathrm{bpm}$ and the mean values of SBP and DBP were $148.8 \pm 29.5 \mathrm{mmHg}$ and 78.7 $\pm 15.1 \mathrm{mmHg}$, respectively. Table 2 shows the structural variables calculated by echocardiography.

Tables 3 and 4 refer to the correlation between EF and age, anthropometric parameters, and clinical variables.

Table 3 shows positive moderate/strong correlations between EF thickness and calc circumference ( $\mathrm{r}=0.5$; $p=$ 0.01 ) , and moderate correlation between EF thickness and weight $(\mathrm{r}=0.4 ; p=0.02)$, BSA $(\mathrm{r}=0.4 ; p=0.02)$ and lean mass ( $\mathrm{r}=0.4 ; p=0.03$ ) (Figure 2). No other statistically significant correlations were found.

As can be seen from Table 4, no statistically significant correlations were found between EF and previous history of cardiovascular disease or any of the clinical variables studied.

Table 5 correlates EF with LVM (corrected for BSA), left atrial and right atrial areas, LV shortening fraction and the LV end-diastolic diameter.

Table 5 shows a positive, but a low to moderate correlation $(\mathrm{r}=0.3 ; p=0.04)$ between EF thickness and LV end-diastolic diameter (Figure 3). For the remaining echocardiographic variables evaluated, no statistically significant correlations were found.

Figure 4 shows the measurement of the EF in two extreme cases, representative of the sample (highest EF value - panel A; lowest EF value - panel B). The participant with the highest EF value was male, 89 years, body weight of $95.5 \mathrm{~kg}$, BSA of $2.03 \mathrm{~m}^{2}$, BMI of $34.7 \mathrm{~kg} / \mathrm{m}^{2}$, waist/hip ratio of 1.08 , CC of $36.5 \mathrm{~cm}$, lean mass of $33 \%$ and fat mass of $37 \%$, presenting with hypertension, dyslipidemia and diabetes. On the other hand, the participant with the lowest EF value was an 85-year-old man, body weight of $63.5 \mathrm{~kg}$, BSA of $1.68 \mathrm{~m}^{2}$, BMI of $24.2 \mathrm{~kg} / \mathrm{m}^{2}$, waist/hip ratio of 0.89 , CC of $34.5 \mathrm{~cm}$, lean mass of $26 \%$ and fat mass of $16 \%$, dyslipidemic. This comparative analysis suggests the tendency of a positive correlation of EF with body weight and a more unfavorable clinical profile.

\section{Discussion and Conclusions}

During the aging process, there is a decrease in lean mass, increase in fat mass and a redistribution of adipose tissue to the trunk and viscera. ${ }^{43} \mathrm{EF}$ is a component of visceral fat, distributed around the heart, located between the myocardial surface and the visceral layer of the pericardium. ${ }^{5-13}$ Iacobellis et al., ${ }^{13}$ found a wide variation in EF thickness (1-23 mm), which probably reflects not only a high variation in the distribution of visceral fat, ${ }^{14}$ 
Table 1 - General characteristics of the sample

\begin{tabular}{|c|c|c|c|c|c|c|c|c|c|}
\hline \multirow{2}{*}{ Variables } & \multicolumn{3}{|c|}{ Women } & \multicolumn{3}{|c|}{ Men } & \multicolumn{3}{|c|}{ Total } \\
\hline & Minimum & Maximum & Mean \pm SD & Minimum & Maximum & Mean \pm SD & Minimum & Maximum & Mean \pm SD \\
\hline Age (years) & 65 & 92 & $82.9 \pm 7.4$ & 66 & 90 & $79.2 \pm 8.7$ & 65 & 92 & $81.9 \pm 7.8$ \\
\hline Weight (kg) & 37.1 & 86.2 & $63.5 \pm 10.7$ & 53.8 & 95.5 & $72.1 \pm 12.2$ & 37.1 & 95.5 & $65.8 \pm 11.6$ \\
\hline Height (cm) & 137 & 160 & $149.0 \pm 6.6$ & 149 & 172 & $164.1 \pm 7.3$ & 137 & 172 & $153.0 \pm 9.5$ \\
\hline $\operatorname{BSA}\left(\mathrm{m}^{2}\right)$ & 1.2 & 1.8 & $1.6 \pm 0.2$ & 1.5 & 2 & $1.8 \pm 0.2$ & 1.2 & 2 & $1.6 \pm 0.2$ \\
\hline BMI $\left(\mathrm{Kg} / \mathrm{m}^{2}\right)$ & 19.8 & 37.3 & $28.8 \pm 4.4$ & 24.2 & 34.7 & $26.9 \pm 3.4$ & 19.8 & 37.3 & $28.2 \pm 4.1$ \\
\hline $\mathrm{AC}(\mathrm{cm})$ & 84 & 122 & $102.3 \pm 8.8$ & 79 & 115 & $100.4 \pm 10.1$ & 79 & 122 & $101.7 \pm 9.0$ \\
\hline LM (\%) & 13.3 & 24.7 & $18.8 \pm 2.9$ & 24 & 33.1 & $28.1 \pm 3.2$ & 13.3 & 33.1 & $21.5 \pm 5.2$ \\
\hline FM (\%) & 10.1 & 44.4 & $27.5 \pm 8.4$ & 6.8 & 37 & $21.8 \pm 8.7$ & 6.8 & 44.4 & $25.9 \pm 8.7$ \\
\hline $\mathrm{CC}(\mathrm{cm})$ & 28 & 45.5 & $34.0 \pm 3.8$ & 31 & 36.5 & $33.9 \pm 1.8$ & 28 & 45.5 & $34.0 \pm 3.3$ \\
\hline HR (bpm) & 53 & 102 & $70.2 \pm 11.1$ & 44 & 90 & $64.7 \pm 12.6$ & 44 & 102 & $68.7 \pm 11.6$ \\
\hline $\begin{array}{l}\mathrm{SBP}(\mathrm{mmHg}) \\
(\mathrm{mm}(\mathrm{mmHg})\end{array}$ & 92 & 238 & $147.5 \pm 31.2$ & 125 & 200 & $152.4 \pm 25.7$ & 92 & 238 & $148.8 \pm 29.5$ \\
\hline DBP (mmHg) & 56 & 135 & $79.9 \pm 15.3$ & 46 & 90 & $75.4 \pm 14.8$ & 46 & 135 & $78.7 \pm 15.1$ \\
\hline
\end{tabular}

Table 2 - Structural variables calculated by echocardiography

\begin{tabular}{|c|c|c|c|c|c|c|c|c|c|}
\hline \multirow[b]{2}{*}{ Variables } & \multicolumn{3}{|c|}{ Women } & \multicolumn{3}{|c|}{ Men } & \multicolumn{3}{|c|}{ Total } \\
\hline & Minimum & Maximum & Mean \pm SD & Minimum & Maximum & Mean \pm SD & Minimum & Maximum & Mean \pm SD \\
\hline LVESD (mm) & 26 & 46 & $33.9 \pm 3.8$ & 35 & 48 & $38.6 \pm 4.1$ & 26 & 48 & $35.2 \pm 4.4$ \\
\hline LVEDD (mm) & 41 & 63 & $52.3 \pm 5.1$ & 55 & 64 & $59.2 \pm 3.5$ & 41 & 64 & $54.2 \pm 5.6$ \\
\hline PWd (mm) & 6.7 & 8.2 & $7.4 \pm 0.4$ & 7.2 & 8.7 & $7.7 \pm 0.5$ & 6.7 & 8.7 & $7.5 \pm 0.4$ \\
\hline IVSd (mm) & 6.7 & 9 & $7.5 \pm 0.6$ & 7.2 & 8.7 & $7.7 \pm 0.6$ & 6.7 & 9 & $7.5 \pm 0.6$ \\
\hline AOR_D (mm) & 22 & 35 & $29.5 \pm 2.8$ & 29 & 40 & $34.9 \pm 3.7$ & 22 & 40 & $30.9 \pm 3.8$ \\
\hline LA_D (mm) & 27 & 53 & $36.8 \pm 5.9$ & 32 & 53 & $38.9 \pm 6.2$ & 27 & 53 & $37.4 \pm 5.9$ \\
\hline LVSF (\%) & 28 & 41 & $34.9 \pm 3.3$ & 24 & 38 & $34.8 \pm 4.5$ & 24 & 41 & $34.9 \pm 3.6$ \\
\hline LVM/BSA $\left(\mathrm{g} / \mathrm{m}^{2}\right)$ & 60 & 128 & $86.0 \pm 15.8$ & 82 & 120 & $99.7 \pm 12.9$ & 60 & 128 & $89.6 \pm 16.1$ \\
\hline $\mathrm{EF}(\mathrm{mm})$ & 4 & 8 & $5.2 \pm 0.9$ & 4 & 9 & $6.0 \pm 1.4$ & 4 & 9 & $5.4 \pm 1.1$ \\
\hline \multicolumn{10}{|c|}{$\begin{array}{l}\text { SD: Standard deviation, LVESD: Left ventricular end-systolic diameter, LVEDD: Left ventricular end-diastolic diameter, PWd: Left ventricular posterior } \\
\text { wall end-diastolic thickness, IVSd: Interventricular septum end-diastolic thickness, AOR_D: Aortic root diameter, LA_D: Left atrial diameter, LVSF: Left } \\
\text { ventricular shortening fraction, LVM/BSA: Left ventricular mass corrected for body surface area, EF: Epicardial fat. }\end{array}$} \\
\hline
\end{tabular}


Table 3 - Correlation between epicardial fat, age and anthropometric parameters

\begin{tabular}{|c|c|c|c|c|c|c|c|c|c|}
\hline Variables & $\begin{array}{l}\text { Age } \\
\text { (anos) }\end{array}$ & $\begin{array}{l}\text { Weight } \\
(\mathrm{Kg})\end{array}$ & $\begin{array}{l}\text { Height } \\
\text { (cm) }\end{array}$ & $\begin{array}{l}\text { BSA } \\
(\mathrm{m} 2)\end{array}$ & $\begin{array}{l}\text { BMI } \\
(\mathrm{Kg} / \mathrm{m} 2)\end{array}$ & $\begin{array}{l}\mathrm{AC} \\
(\mathrm{cm})\end{array}$ & $\begin{array}{l}\text { LM } \\
(\%)\end{array}$ & $\begin{array}{l}\text { FM } \\
(\%)\end{array}$ & $\begin{array}{l}\mathrm{CC} \\
(\mathrm{cm})\end{array}$ \\
\hline Pearson's correlation (r) & -0.1 & 0.4 & 0.3 & 0.4 & 0.3 & 0.2 & 0.4 & 0.2 & 0.5 \\
\hline Significance $(p)$ & 0.7 & 0.02 & 0.1 & 0.02 & 0.2 & 0.2 & 0.03 & 0.2 & 0.01 \\
\hline
\end{tabular}

BSA: Body surface area, BMI: Body mass index, AC: Abdominal circumference, LM: Lean mass, FM: Fat mass, CC: calf circumference

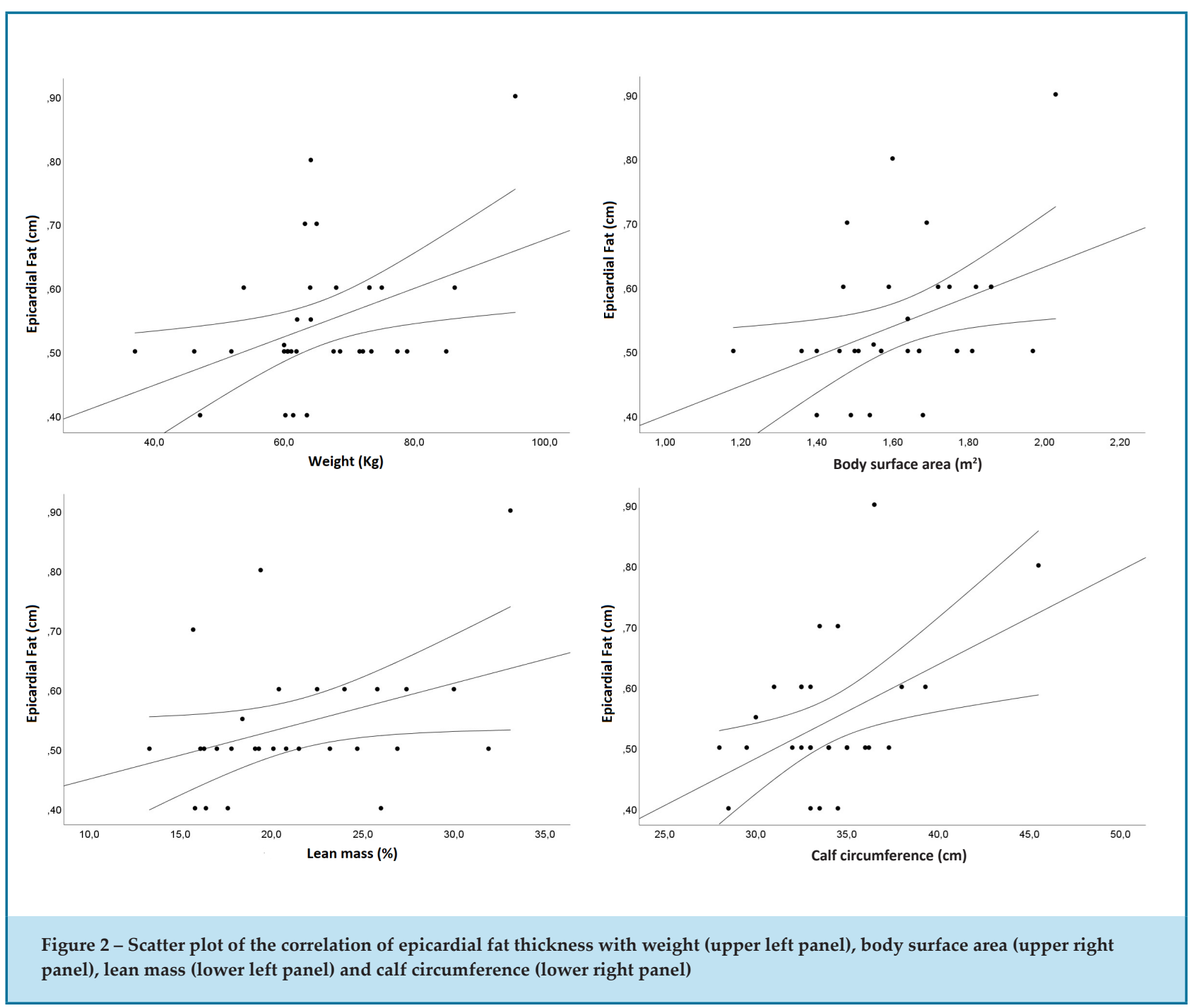


Table 4 - Correlation between epicardial fat thickness, history of cardiovascular disease and clinical variables

\begin{tabular}{|c|c|c|c|c|c|c|}
\hline Variables & $\begin{array}{c}\text { Cardiovascular } \\
\text { history }\end{array}$ & Hypertension & Dyslipidemia & Diabetes & $\begin{array}{c}\text { SBP } \\
(\mathrm{mmHg})\end{array}$ & $\begin{array}{c}\text { DBP } \\
(\mathrm{mmHg})\end{array}$ \\
\hline $\begin{array}{l}\text { Point-biserial correlation } \\
\text { coefficient (rpbiss) }\end{array}$ & -0.2 & -0.1 & -0.1 & -0.3 & 0.2 & 0.1 \\
\hline Significance $(p)$ & 0.2 & 0.8 & 0.5 & 0.2 & 0.4 & 0.5 \\
\hline
\end{tabular}

Table 5 - Correlation between epicardial fat thickness and structural echocardiographic parameters

\begin{tabular}{lccccc}
\hline Variables & $\begin{array}{c}\text { LVM/BSA } \\
\left(\mathbf{g} / \mathbf{m}^{2}\right)\end{array}$ & $\begin{array}{c}\text { LA_A } \\
\left(\mathbf{c m}^{2}\right)\end{array}$ & $\begin{array}{c}\text { RA_A } \\
\left(\mathbf{c m}^{2}\right)\end{array}$ & $\begin{array}{c}\text { LVSF } \\
(\%)\end{array}$ & $\begin{array}{c}\text { LVEDD } \\
(\mathbf{m m})\end{array}$ \\
Pearson's correlation $(\mathrm{r})$ & 0.2 & -0.2 & -0.04 & 0.2 & 0.3 \\
\hline Significance $(p)$ & 0.2 & 0.3 & 0.8 & 0.3 & 0.04 \\
\hline
\end{tabular}

LVM/BSA: Left ventricular mass corrected for body surface area, LA_A : Left atrial area, RA_A: Right atrial area, LVSF: Left ventricular shortening fraction, LVEDD: Left ventricular end-diastolic diameter

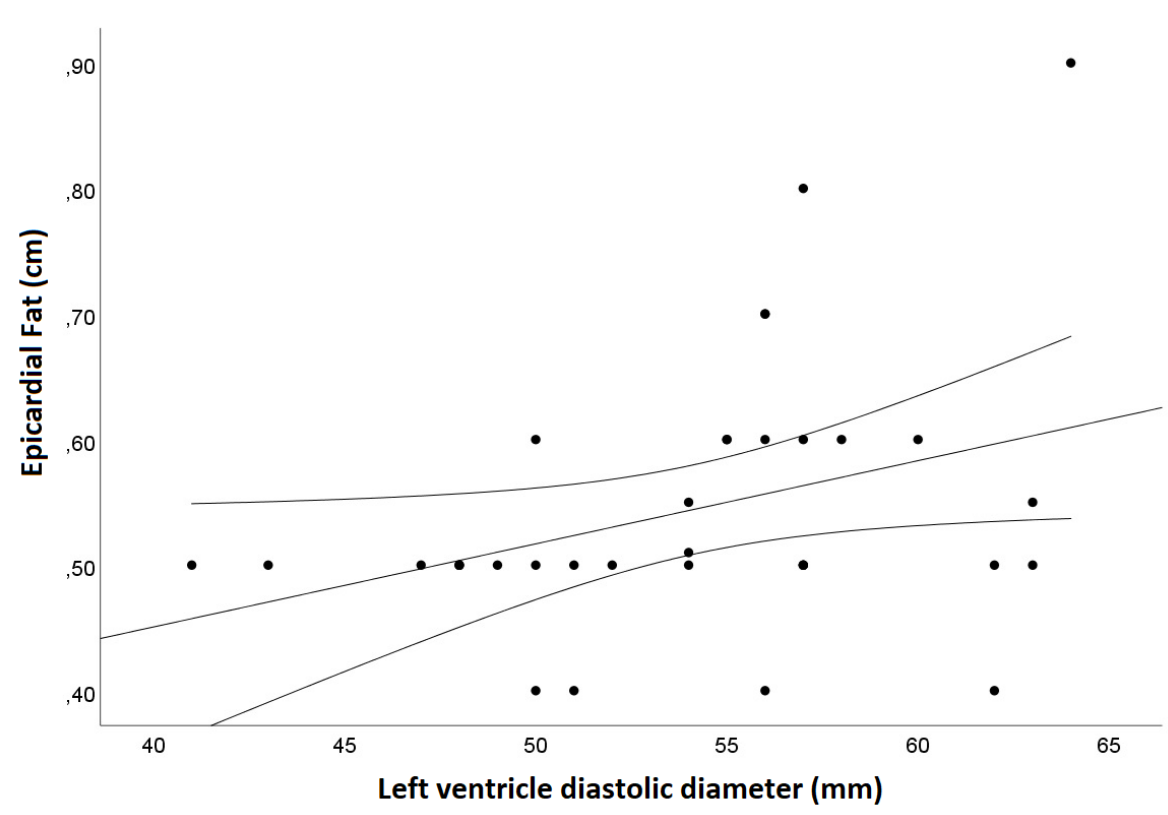

Figure 3 - Scatter plots correlating epicardial fat thickness with left ventricular diastolic diameter 

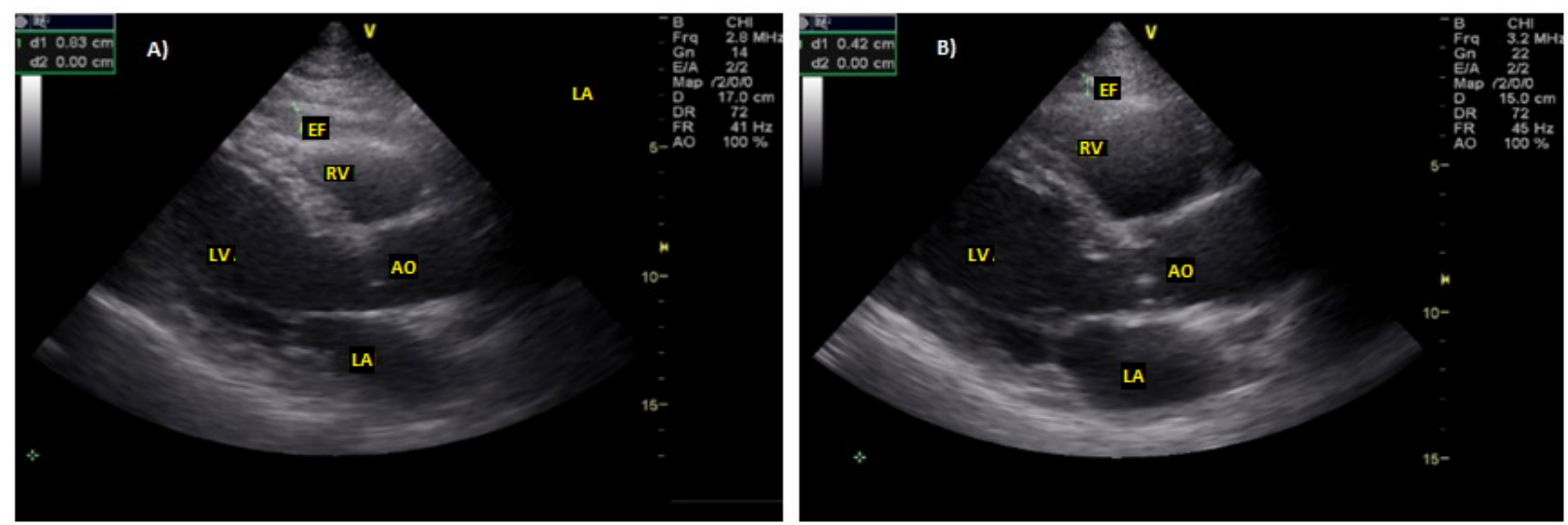

Figure 4 - Representation of epicardial fat assessment in two study participants. Panel A) participant with a high epicardial fat thickness; Panel B) participant with a low epicardial fat thickness. Legend: EF: epicardial fat; RV: right ventricle; LV: left ventricle; AO: aorta; LA: left atrium

but also in the clinical and demographic characteristics of the studied populations. ${ }^{8}$

In our study, mean EF thickness was $5.4 \pm 1.1 \mathrm{~mm}$, with higher values in males $(6.0 \pm 1.4 \mathrm{~mm}$ vs $5.2 \pm$ $0.9 \mathrm{~mm})$. While Iacobellis et al., ${ }^{11,12}$ Calabuig et al., ${ }^{19}$ and Alexopoulos et al., ${ }^{31}$ (these using computerized tomography) found similar results, different findings have been reported by other groups. ${ }^{7,25-32}$ The correlation between EF and age has not been consensual also; some studies have shown a correlation between these variables, ${ }^{9,19,22,24,25,27,28,31}$ in contrast to others. ${ }^{7,11-12,29-30}$

The association between EF and obesity has been widely described, since there is a predisposition for increased EF in obese individuals compared to nonobese individuals. ${ }^{13,18,19,27,30,36,37}$ However, in our study, no statistically significant correlations were found between EF and BMI, possibly because our sample was not overweight $(63.5 \pm 10.7 \mathrm{~kg}$ for women and $72.1 \pm 12.2 \mathrm{~kg}$ for men). These are in agreement with Bertaso et al. ${ }^{8}$ and Magliano et al., ${ }^{9}$ but in contrast to others ${ }^{10-12,22,25,26,29}$ Also, other studies reported statistically significant correlations for the male gender only ${ }^{28}(\mathrm{r}=0.329$ and $p=0.041$ in men vs $r=0.105$ and $p=0.362$ in women). Such discrepancy in results may be due to the characteristics and age of the studied populations.

In our study, we did not find a correlation between $\mathrm{EF}$ and dyslipidemia or diabetes. Similar results were published by Kim et al., ${ }^{26}$ for dyslipidemia $(p=0.738)$, and Mazzoccoli et al., ${ }^{27}(p=0.098)$ and Alexopoulos et al., ${ }^{31}(p=0.226$ using CT) for diabetes, but contradictory results were observed by Mazzoccoli et al. ${ }^{27}(p=0.01)$ and Alexopoulos et al., ${ }^{31}(p<0.05)$ for dyslipidemia and Iacobellis et al., ${ }^{44}$ for type 1 diabetes. Moreover, Iacobellis et al., ${ }^{44}$ reported that type 1 diabetes is associated with excess EF regardless of BMI, since EF thickness was significantly higher in diabetic individuals compared to non-diabetics $(7.2 \pm 2.1 \mathrm{~mm}$ vs $4.9 \pm 2.5 \mathrm{~mm} ; p<0.01)$. Similar results were observed by Kim et al., ${ }^{26}(p=0.022)$ and Li et al., ${ }^{45}$

With aging, calcium deposition and loss of elastic fibers in the middle layer of the arteries are observed, leading to a decrease in their distensibility. ${ }^{46}$ In the aortic artery, this fact stimulates the development of hypertension, diastolic dysfunction and heart failure. ${ }^{47-49}$ Although in our study $35.3 \%$ of the individuals had isolated systolic hypertension, no statistically significant correlations were found between EF and hypertension. However, in the study by Mazzoccoli et al., ${ }^{27} \mathrm{Kim}$ et al., ${ }^{26}$ and Alexopoulos et al., ${ }^{31}$ EF thickness was significantly higher in hypertensive individuals. Also, Natale et al., ${ }^{24}$ in a study performed on 459 hypertensive individuals, found an increase in SBP $(p=0.01)$ and a reduction in DBP $(p=0.01)$ when the EF thickness was greater than $7 \mathrm{~mm}$. Thus, they reported the existence of statistically significant positive correlations $(\mathrm{r}=0.35 ; p<0.0001)$ between EF thickness and SBP, and negative correlations between EF thickness and DBP $(r=-0.13 ; p<0.01)$. However, Iacobellis et al., ${ }^{29}$ found statistically significant correlations only for DBP ( $\mathrm{r}=0.589 ; p=0.02)$, and Wang et al., ${ }^{34}$ (using CT) did not obtain statistically significant results neither with SBP nor with DBP. 
Regarding the anthropometric parameters, in our study, we found statistically significant correlations between EF and weight, BSA, lean mass and CC. Shetty et al..$^{25}(\mathrm{r}=0.346 ; p<0.001)$ and Willens et al. ${ }^{30}(\mathrm{r}=0.51 ; p=$ 0.011) obtained similar results, but only for weight. Using CT, Nakazato et al., ${ }^{33}$ Wang et al., ${ }^{34}$ and Alexopoulos et al., ${ }^{31}$ obtained statistically significant correlations between EF and weight, BMI, height, and abdominal circumference. Other studies refer the existence of statistically significant correlations between EF thickness and abdominal circumference ${ }^{10-13,19,22,25,28,29}$ and between EF thickness and fat mass. ${ }^{11,12}$

Among the echocardiographic variables evaluated in our study, statistically significant results were found between EF thickness and LV end-diastolic diameter only. Iacobellis et al., ${ }^{29}$ also obtained statistically significant results for the correlation between EF thickness and LVMI $(\mathrm{r}=0.755 ; p=0.01)$, although Natale et al., ${ }^{24}$ referred that this correlation is only significant for values of EF thickness higher than 7 $\mathrm{mm}$. Thus, apparently, the increase of the EF thickness seems to be associated with $\mathrm{LVH},{ }^{14,18}$ and Kim et al., ${ }^{26}$ even reported that, among hypertensive individuals, EF was higher in those with LVH $(7.5 \pm 2.3 \mathrm{~mm}$ vs 6.6 $\pm 1.9 \mathrm{~mm} ; p=0.034$ ).

\section{Study Limitations}

The small sample size and the fact that the studied population was older when compared with previous studies may have influenced the results. Although the use of more sophisticated methods for statistical analysis was limited by the small sample size, this is one of the few studies that evaluated EF and its relationship with clinical and anthropometric characteristics in old adults. Since the results were obtained from a cross-sectional analysis, no information regarding the variation in the $\mathrm{EF}$ content in the heart with ageing was available.

\section{Conclusion and Future Perspectives}

The results obtained demonstrate that EF is a common finding in the old adult, especially in males, and correlates with anthropometric parameters and LV end-diastolic diameter. Additional studies may give important contributions to a better understanding of the relationship between aging and EF. A cohort study, with a follow-up of an extended cohort during the aging process, will be important to evaluate the course of EF deposition throughout life, and determine the risks associated with it. Besides, a future challenge will be to understand if multidisciplinary and tailored interventions directed at optimizing functionality and promoting quality of life, including actions such as individualized physical exercise, and nutritional and therapeutic counseling, can be effective strategies to reduce $\mathrm{EF}$ and the associated risks.

\section{Author Contributions}

Conception and design of the research: Pereira $\mathrm{T}$ and Castanheira J. Acquisition of data: Pereira T, Castanheira J, Nunes C. Analysis and interpretation of the data: Pereira T, Castanheira J, Nunes C. Statistical analysis: Pereira T, Castanheira J, Nunes C. Obtaining financing : Pereira T. Writing of the manuscript: Nunes C, Castanheira J. Critical revision of the manuscript for intellectual content: Pereira T, Castanheira J.

\section{Potential Conflict of Interest}

No potential conflict of interest relevant to this article was reported.

\section{Sources of Funding}

This work is co-financed by the European Regional Development Fund (ERDF), through the partnership agreement Portugal 2020 - Regional Operation Program CENTRO 2020, under the project CENTRO-01-0145FEDER-023369 AGA@4life: AGA - Comprehensive Geriatric Approach to promote an active and healthy aging - implementation of an integrated and multidisciplinary intervention program.

\section{Study Association}

This study is not associated with any thesis or dissertation work.

\section{Ethics approval and consent to participate}

This study was approved by the Ethics Committee of the Instituto Politécnico de Coimbra under the protocol number $8 / 2018$. All the procedures in this study were in accordance with the 1975 Helsinki Declaration, updated in 2013. Informed consent was obtained from all participants included in the study. 


\section{References}

1. $\mathrm{Xu} \mathrm{B}$, Daimon M. Cardiac aging phenomenon and its clinical features by echocardiography. J Echocardiogr. 2016;14(4):139-45.

2. Sahasakul Y, Edwards WD, Naessens JM, Tajik AJ. Age-related changes in aortic and mitral valve thickness: implications for two-dimensional echocardiography based on an autopsy study of 200 normal human hearts. Am J Cardiol. 1988;62(7):424-30.

3. Keller KM, Howlett SE. Sex differences in the biology and pathology of the aging heart. Can J Cardiol. 2016;32(9):1065-73.

4. Martins Jr LM. The elderly and heart: valves. Ponto de Vista. 2016;18(1):58-9.

5. Nagy E, Jermendy AL, Merkely B, Maurovich-Horvat P. Clinical importance of epicardial adipose tissue. Arch Med Sci. 2017;13(4):864-74.

6. Talman AH, Psaltis PJ, Cameron JD, Meredith IT, Seneviratne SK, Wong DT. Epicardial adipose tissue: far more than a fat depot. Cardiovasc Diagn Ther. 2014;4(6):416-29.

7. Meenakshi K, Rajendran M, Srikumar S, Chidambaram S. Epicardial fat thickness: a surrogate marker of coronary artery disease - assessment by echocardiography. Indian Heart J. 2016;68(3):336-41.

8. Bertaso AG, Bertol D, Duncan BB, Foppa M. Epicardial fat: definition, measurements and systematic review of main outcomes. Arq Bras Cardiol. 2013;101(1):18-28.

9. Silva CM, Nascimento CAS, Castelli RC, Saraiva RC, Pustilnic A. Reference values for epicardial fat diameter measured by echocardiography in a normal population. Rev Bras Ecocardiogr Imagem Cardiovasc. 2011;24(1):24-9.

10. Sharda M, Nigam H, Meena SR, Soni A, Singh A, Sharma N. Correlation and comparison of epicardial adipose tissue with sagittal abdominal diameter and other anthropometric and biochemical variables of metabolic syndrome. J Assoc Physicians India. 2017;65(5):34-40.

11. Iacobellis G, Ribaudo MC, Assael F, Vecci E, Tiberti C, Zappaterreno A, et al. Echocardiographic epicardial adipose tissue is related to anthropometric and clinical parameters of metabolic syndrome: a new indicator of cardiovascular risk. J Clin Endocrinol Metab. 2003;88(11):5163-8.

12. Iacobellis G, Assael F, Ribaudo MC, Zappaterreno A, Alessi G, Di Mario $U$, et al. Epicardial fat from echocardiography: a new method for visceral adipose tissue prediction. Obes Res. 2003;11(2):304-10.

13. Iacobellis G, Willens HJ, Barbaro G, Sharma AM. Threshold values of high-risk echocardiographic epicardial fat thickness. Obesity (Silver Spring). 2008;16(4):887-92.

14. Iacobellis G, Willens HJ. Echocardiographic epicardial fat: a review of research and clinical applications. J Am Soc Echocardiogr. 2009;22(12):1311-9.

15. Iacobellis G, Corradi D, Sharma AM. Epicardial adipose tissue: anatomic, biomolecular and clinical relationships with the heart. Nat Clin Pract Cardiovasc Med. 2005;2(10):536-43.

16. Silaghi AC, Pais R, Valea A, Mironiuc A, Silaghi H. Epicardial adipose tissue and relationship with coronary artery disease. Cent Eur J Med. 2011;6(3):251-62.

17. Matloch Z, Kotulák T, Haluzík M. The role of epicardial adipose tissue in heart disease. Physiol Res. 2015;65(1):23-32.

18. Silaghi A, Piercecchi-Marti MD, Grino M, Leonetti G, Alessi MC, Clement $\mathrm{K}$, et al. Epicardial adipose tissue extent: relationship with age, body fat distribution, and coronaropathy. Obesity (Silver Spring). 2008;16(11):2424-30.

19. Calabuig Á, Barba J, Guembe MJ, Díez J, Berjón J, Martínez-Vila E, et al. Epicardial adipose tissue in the general middle-aged population and its association with metabolic syndrome. Rev Esp Cardiol (Engl Ed). 2017;70(4):254-60.
20. Iacobellis G. Local and systemic effects of the multifaceted epicardial adipose tissue depot. Nat Rev Endocrinol. 2015;11(6):363-71.

21. Iacobells G, Malavazos AE, Corsi MM. Epicardial fat: from the biomolecular aspects to the clinical practice. Int J Biochem Cell Biol. 2011;43(12):1651-4.

22. Jeong JW, Jeong MH, Yun KH, Oh SK, Park EM, Kim YK, et al. Echocardiographic epicardial fat thickness and coronary artery disease. Circ J. 2007;71(4):536-9.

23. Mookadam F, Goel R, Alharthi MS, Jiamsripong P, Cha S. Epicardial fat and its association with cardiovascular risk: a cross-sectional observational study. Heart Views. 2010;11(3):103-8.

24. Natale F, Tedesco MA, Mocerino R, Simone V, Di Marco GM, Aronne L, et al. Visceral adiposity and arterial stiffness: echocardiographic epicardial fat thickness reflects, better than waist circumference, carotid arterial stiffness in a large population of hypertensives. Eur J Echocardiogr. 2009;10(4):549-55.

25. Shetty R, Vivek G, Naha K, Nayak K, Goyal A, Dias LS. Correlation of epicardial fat and anthropometric measurements in Asian-Indians: a community based study. Avicenna J Med. 2012;2(4):89-93.

26. Kim SA, Kim MN, Shim WJ, Park SM. Epicardial adipose tissue is related to cardiac function in elderly women, but not in men. Nutr Metab Cardiovasc Dis. 2017;27(1):41-7.

27. Mazzoccoli G, Dagostino MP, Greco A. Age-related changes of epicardial fat thickness. Biomed Prev Nutr. 2012;2(1):38-41.

28. Karadag B, Ozulu B, Ozturk FY, Oztekin E, Sener N, Altuntas Y. Comparison of epicardial adipose tissue (EAT) thickness and anthropometric measurements in metabolic syndrome (MS) cases above and under the age of 65. Arch Gerontol Geriatr. 2011;52(2):e79-84.

29. Iacobellis G, Ribaudo MC, Zappaterreno A, Iannucci CV, Leonetti F. Relation between epicardial adipose tissue and left ventricular mass. Am J Cardiol. 2004;94(8):1084-7.

30. Willens HJ, Byers P, Chirinos JA, Labrador E, Hare JM, de Marchena E. Effects of weight loss after bariatric surgery on epicardial fat measured using echocardiography. Am J Cardiol. 2007;99(9):1242-5.

31. Alexopoulos N, McLean DS, Janik M, Arepalli CD, Stillman AE, Raggi $P$. Epicardial adipose tissue and coronary artery plaque characteristics. Atherosclerosis. 2010;210(1):150-4.

32. Shim IK, Cho KI, Kim HS, Heo JH, Cha TJ. Impact of gender on the association of epicardial fat thickness, obesity, and circadian blood pressure pattern in hypertensive patients. J Diabetes Res. 2015;2015:924539.

33. Nakazato R, Rajani R, Cheng VY, Shmilovich H, Nakanishi R, Otaki Y, et al. Weight change modulates epicardial fat burden: a 4-year serial study with non-contrast computed tomography. Atherosclerosis. 2012;220(1):139-44.

34. Wang CP, Hsu HL, Hung WC, Yu TH, Chen YH, Chiu CA, et al. Increased epicardial adipose tissue (EAT) volume in type 2 diabetes mellitus and association with metabolic syndrome and severity of coronary atherosclerosis. Clin Endocrinol (Oxf). 2009;70(6):876-82.

35. Mazurek T, Zhang L, Zalewski A, Mannion JD, Diehl JT, Arafat H, et al. Human epicardial adipose tissue is a source of inflammatory mediators. Circulation. 2003;108(20):2460-6.

36. Iacobellis G, Leonetti F, Singh N, Sharma AM. Relationship of epicardial adipose tissue with atrial dimensions and diastolic function in morbidly obese subjects. Int J Cardiol. 2007;115(2):272-3.

37. Iacobellis G, Singh N, Wharton S, Sharma AM. Substantial changes in epicardial fat thickness after weight loss in severely obese subjects. Obesity (Silver Spring). 2008;16(7):1693-7.

38. Kim MK, Tomita T, Kim MJ, Sasai H, Maeda S, Tanaka K. Aerobic exercise training reduces epicardial fat in obese men. J Appl Physiol. 2009;106(1):5-11. 
39. Singh N, Singh H, Khanijoun HK, Iacobellis G. Echocardiographic assessment of epicardial adipose tissue -a marker of visceral adiposity. Mcgill J Med. 2007;10(1):26-30.

40. Lang RM, Badano LP, Mor-Avi V, Afilalo J, Armstrong A, Ernande $\mathrm{L}$, et al. Recommendations for cardiac chamber quantification by echocardiography in adults: an update from the American Society of Echocardiography and the European Association of Cardiovascular Imaging. J Am Soc Echocardiogr. 2015;28(1):1-39.

41. Mitchell C, Rahko PS, Blauwet LA, Ogunyankin KO, Palma RA, Velasquez EJ, et al. Guidelines for performing a comprehensive transthoracic echocardiographic examination in adults: recommendations from the American Society of Echocardiography. J Am Soc Echocardiogr. 2019;32(1):1-64.

42. Hopkins WG, Marshall SW, Batterham AM, Hanin J. Progressive statistics for studies in sports medicine and exercise science. Med Sci Sports Exerc. 2009;41(1):3-13.

43. Dey DK, Rothenberg E, Sundh V, Bosaeus I, Steen B. Height and body weight in the elderly. I. A 25-year longitudinal study of a population aged 70 to 95 years. Eur J Clin Nutr. 1999;53(12):905-14.
44. Iacobellis G, Diaz S, Mendez A, Goldberg R. Increased epicardial fat and plasma leptin in type 1 diabetes independently of obesity. Nutr Metab Cardiovasc Dis. 2014;24(7):725-9.

45. Li Y, Liu B, Li Y, Jing X, Deng S, Yan Y, et al. Epicardial fat tissue in patients with diabetes mellitus: a systematic review and meta-analysis. Cardiovasc Diabetol. 2019;18(1):3.

46. Chobanian AV, Bakris GL, Black HR, Cushman WC, Green LA, Izzo Jr JL, et al. The seventh report of the joint national committee on prevention, detection, evaluation, and treatment of high blood pressure: the JNC 7 report. JAMA. 2003;289(19):2560-72.

47. Wajngarten M. O coração no idoso. Jornal Diagnósticos em Cardiologia. 2010;13(43):1-9.

48. Cheitlin MD. Cardiovascular physiology- changes with aging. Am J Geriatr Cardiol. 2003;12(1):9-13.

49. Hall JE. Tratado de fisiologia médica. 12a ed. Rio de Janeiro: Elsevier; 2011. 